\title{
Adapting Engineering Design Model to Middle Eastern Culture:

\author{
The Colorado School of Mines Brings \\ Engineering Design to The Petroleum \\ Institute
}

\author{
SUZANNE W. SCOTT \\ The Petroleum Institute \\ Abu Dhabi \\ United Arab Emirates
}

\begin{abstract}
:
The 2003-4 academic year at the Petroleum Institute in Abu Dhabi has been the site of a rewarding and revealing experiment in implementing Western engineering design to higher academia in the Arab world. With funding from a consortium of major oil companies including The Abu Dhabi National Oil Company, Shell, BP, and JODCO and led by a team from the Colorado School of Mines, the Petroleum Institute was established in 2001. The goals of the Institute include educating UAE nationals in fields of engineering (Chemical, Electrical, Mechanical, Petroleum and Petroleum Geosciences) that will serve the on-going needs of the oil and gas industry in the Gulf region. The Abu Dhabi National Oil Company signed a nine-year agreement with the Colorado School of Mines to provide leadership in programs and curriculum design, with the goal of achieving ABET accreditation for the Petroleum Institute. As part of that effort, experienced faculty from CSM were brought over during the 2003-4 academic year to establish an engineering design program on the new campus. The program, modeled after CSM's cutting edge EPICS Program (Engineering Practices Introductory Course Sequence) was given the new acronym of STEPS (Strategies for Team-based Engineering Problem Solving). The translation of the program to the other-cultural setting has brought challenges to all major emphases of the Program - teamwork, communications, problem-solving, mentoring, and graphics. This paper will attempt to identify the unique Arabic cultural aspects which either resist or embrace the Western design model, and begin to identify a common core curriculum for engineering design programs in the Middle East.
\end{abstract}

"Proceedings of the 2005 American Society for Engineering education Annual Conference \& Exposition Copyright $\mathrm{C} 2005$, American Society for Engineering Education”, 


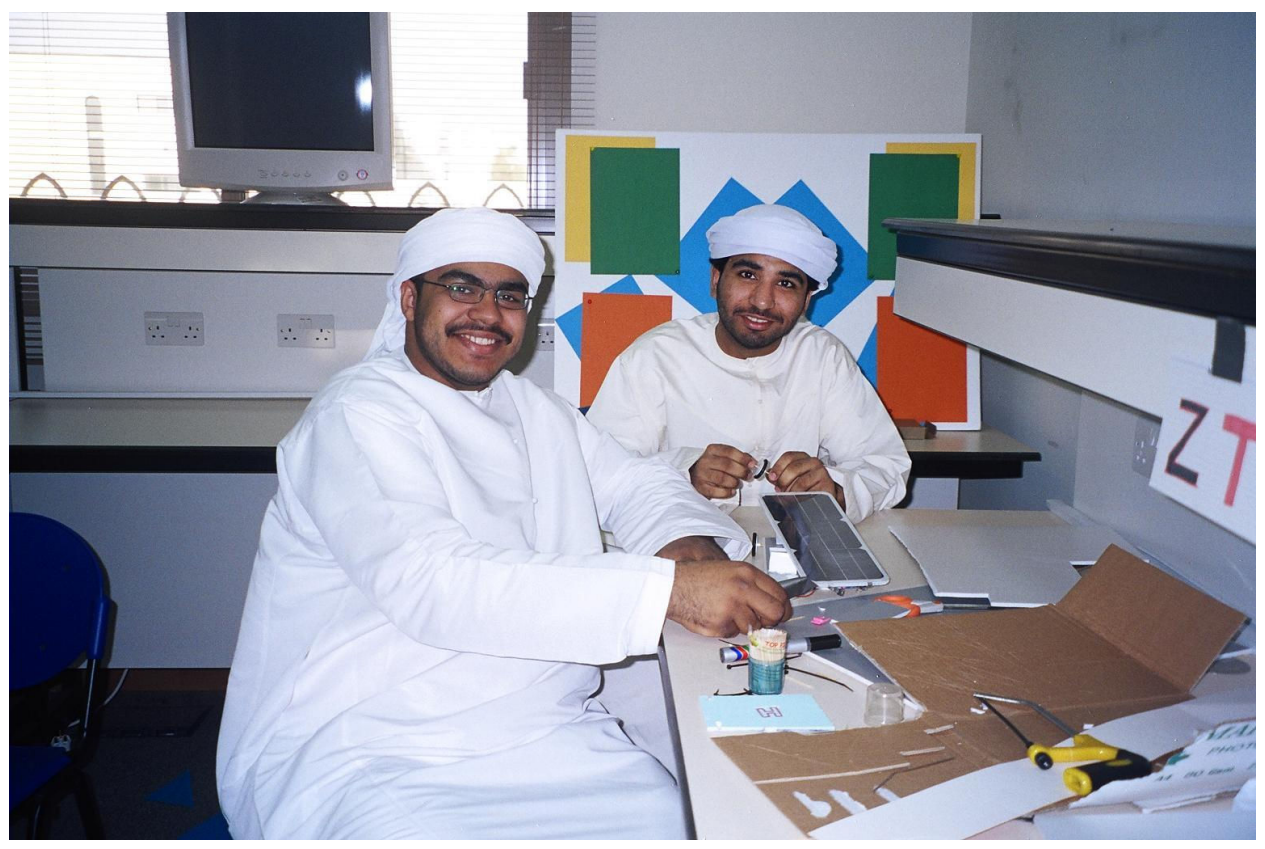

FiguRE 1

\section{STEPS STUDENTS PREPARE POSTERS FOR THE MINIATURE SOLAR RACE CAR COMPETITION AT THE PETROLEUM INSTITUTE}

\section{INTRODUCTION}

The translation of an engineering design program to a foreign culture offers many challenges, including overcoming the broad barriers of language, religion, values, manners, and ethnocentrism. In addition, the unique aspects of engineering design - problem solving, decision-making, teamwork, and communication skills are put to the test when transferred to a new cultural plane. The 2003-4 academic year at the Petroleum Institute in Abu Dhabi has been the site of a rewarding and revealing experiment in implementing Western engineering design to higher academia in the Arab world.

Experienced design faculty from the Colorado School of Mines were brought to the Petroleum Institute in the Fall of 2003 to foster and implement a program modeled after the widely acclaimed CSM EPICS Program (Engineering Practices Introductory Course Sequence). The fledgling program acquired the new acronym STEPS (Strategies for Team-Based Engineering Problem Solving), and was soon faced with the challenge of introducing the "steps" of engineering design to a culture of students vastly different from Western students in origin, experience, and custom. The iterative process of engineering design is characterized by a series of distinct functions: identifying needs, defining options, making decisions, gathering data, preparing a plan, and implementing a plan. Demonstrating these functions, along with introducing the students to open-ended problem solving, produced both universal and culturally distinctive results.

This paper will demonstrate various cultural distinctions affecting the progress and success of adapting an engineering model to a Middle Eastern culture. In a sense, this paper reflects the colonization of a Western academic community in the Middle East, and the resulting anthropological dynamics. It is also at its core an attempt at communication, understanding, and the 
exchange of good will between two cultures. First, an introduction to the participants and early history of the Petroleum Institute will lay the foundation for this experiment in trans-cultural learning.

\section{The Petroleum Institute}

With funding from a consortium of major oil companies including The Abu Dhabi National Oil Company, Shell, BP, and JODCO and led by a team from the Colorado School of Mines, the Petroleum Institute was established in 2001. The goals of the Institute include educating United Arab Emirates nationals in fields of engineering (Chemical, Electrical, Mechanical, Petroleum and Petroleum Geosciences) that will serve the on-going needs of the oil and gas industry in the Gulf region. In September 2001 the Petroleum Institute enrolled its first students - 140 young men - and began classes taught by 14 instructors. In September 2003 the Institute registered over 400 students who were taught by 60 faculty members who have been recruited worldwide.

Recognizing the longstanding reputation of the Colorado School of Mines for excellence in engineering education and applied sciences as well as its focus on energy and natural resource technologies, The Abu Dhabi National Oil Company signed a nine-year agreement with the Colorado School of Mines to provide leadership in programs and curriculum design, with the goal of achieving ABET accreditation for the Petroleum Institute.

\section{The Colorado School of Mines EPICS Program}

The model for this experiment in trans-cultural engineering education is the Design EPICS (Engineering Practices Introductory Course Sequence) Program at the Colorado School of Mines. Directed by Dr. Robert D. Knecht for the past twelve years, the program is conceived to guide teams of first and second-year engineering students through an authentic design process that calls on decision-making methodology to address technical, open-ended, client-based projects. Mentors (experienced teachers) guide the students through the creative, interactive, and complex decisionmaking process. Teams absorb design process through practice, as they synthesize information, skills, and values. Project solutions are showcased at the end of the semester in written reports, oral presentations and graphics demonstration. Past projects have included designing solar ovens for African communities, interactive playground equipment for children with disabilities, and lunar mining modules that have received NASA's attention.

In the Spring of 2003, CSM faculty members Dr. Robert M. Baldwin, Dr. Ronald Miller, and Dr. Suzanne W. Scott, along with the Petroleum Institute's Chief Academic Officer, Dr. John Golden, began planning the application of the EPICS curriculum to the Petroleum Institute.

\section{The Petroleum Institute's STEPS Program:}

\section{Program CONCEPT}

Teaching students the concepts and practices required to successfully tackle an open-ended engineering design problem is one of the more challenging jobs for any engineering educator. The skills and professional and personal attributes required to solve textbook problems or analyze laboratory data are considerably different than those required for engineering design. The openended nature of design often frustrates students, who are trained to look for the "right" solution rather than choose the best solution from a number of feasible options.

\footnotetext{
"Proceedings of the 2005 American Society for Engineering education Annual Conference \& Exposition Copyright $\mathrm{C} 2005$, American Society for Engineering Education"
} 
The STEPS program is designed to introduce second-year engineering students at the Petroleum Institute to the theoretical and intellectual concepts as well as the practical methods used in engineering design in an integrated two semester sequence at a very early stage in their education. STEPS I presents students with a well defined problem, and then leads them through the process using the concepts of guided design. During STEPS I the students are also given extensive instruction in the application of soft skills that are important to successful design, namely teamwork, project planning, and professional oral and written communications. In the second semester, the students are given an open-ended discipline-specific problem. Faculty advisors serve the role as mentors for this project.

The STEPS program is unique to the United Arab Emirates, and is the first of its kind in the Arabian Gulf region.

\section{Placement of Students in the Program}

One of the first decisions that the new STEPS faculty had to make was choosing the appropriate year level for Arab students in an engineering school to be introduced to engineering design. At the Petroleum Institute, entering students spend two years preparing for the equivalent of a four-year degree program in the West. The first year, called "Foundation," lays intensive groundwork in English, Physical Science, Mathematics, Computing, and Self Study, and is designed to form a bridge between UAE secondary school instruction and the 4-year degree program offered by the PI. Following "Foundation," students are required to complete a "First Year Program" of core courses necessary to success in the degree programs at the PI. A student reaching "Second Year" status at the PI is similar to reaching sophomore, or second-year standing in the West. The committee planning the introduction of the new design program decided that this was the appropriate level for offering it. Like its CSM counterpart, the STEPS Program was divided into two components, STEPS I and STEPS II. While STEPS I introduces the students to design methodology in the context of a generic design-and-build project, STEPS II presents the students with a discipline specific project, and emphasizes application, data analysis, and technical skill.

\section{Course Mission And Student Outcomes}

In an attempt to establish goals for the new program, a Course Mission Statement was created that speaks to the primary components of the program: design process, client-based projects, team skills, communications skills, graphics, and the application of technical skills necessary to the solution of the problem. Specific student outcomes were identified for STEPS I:

- Write an effective technical memo and short engineering report for multiple audiences including a project client

- Present an effective oral briefing to multiple audiences including a project client

- Work in a team environment to design and build an engineering system or device to meet specified project objectives

- Apply engineering design methods to solve an open-ended project for a PI client

- Graphically describe an engineering design 


\section{Course Schedule, Syllabus, ANd Deliverables}

STEPS I classes met three times a week and included 2 hours for project work, 3 hours for computer graphics, and 1 hour for team meetings. STEPS II classes met twice a week -2 hours for project work and 1 hour for team meetings and extra presentations as required. Deliverables for both courses centered on reports and oral presentations that reflect the steps in the correspondence process between team and client.

\section{Projects and Project Competition: Solar Racing Cars and Balsa Wood Bridges}

While planning its first year at the PI, the CSM faculty team considered the kinds of projects that are successful in the CSM EPICS Program. These are design-and-build projects solicited by an authentic client who attends presentations and provides feedback throughout the semester on how effectively teams are meeting his or her requirements. "Client letters" invite the student teams to participate in the project. Students design and build prototypes that are presented at the end of the semester in a poster session. Judges choose the best designs on the basis of creativity, technical skill, ingenuity, and communications skills.

For the first semester of STEPS I, the faculty team chose to have the students design and build miniature solar racing cars; second semester the students constructed balsa wood bridges. Both projects were highlighted in competitions (racing the cars and testing the strength of the bridges) at the end of the terms, and awards were presented to the winning teams. In STEPS II, the discipline specific projects included planning an oil field (Petroleum Geoscience majors), designing chemically powered racing cars (Chemical Engineering majors), and conducting a feasibility study for an oil pipeline (Mechanical Engineering majors).

\section{Adapting Components of the Program to Middle Eastern Culture}

Over the course of the first year, the new STEPS faculty dealt daily with Middle Eastern cultural distinctions in the higher academic world of the UAE compared to that of the United States. Instead of a classroom full of young men and women in various modes of denim, Arab nationals dress in the traditional dishdash and gutra (white robe and headdress) worn every day in public by Islamic men in this part of the world. Faculty mentors encounter an immediate sense of homogeneity in the classroom created by the robes in a men-only environment. How would we foster independent thinking here? Could teamwork be understood and encouraged? How would the students react to the guidance of an adult mentor, as opposed to the expected lecturer? These and other questions were asked and answered over the 2003-4 academic year. The following represent recognized aspects and components of the CSM engineering design model, and how they were realized and received in the UAE.

\section{TEAMWORK AND ARABIAN FRIENDSHIP/ LOYALTY}

Since the fields of engineering and science increasingly demand the use of team decision-making in order to meet the needs of a rapidly developing technological society, the STEPS program (like its CSM counterpart) formed teams of 4-5 students to participate in project problem solving. Since the 
success of any given team relies not only on the individual contributions of team members but in the interaction of team members, we wondered what this culture knew about teams and how they would perform in them. Most of the students had participated on sports teams and were able to identify the best qualities of such teams - leadership, unity, and spirit, but participating on a project team brought new challenges - working with people they didn't know, time and team management, planning and decision-making.

Our Arab students, intensely loyal to relationships, were disappointed that they couldn't choose to be on teams with their best friends. "Brotherhood" among Arabs means loving their friends "for Allah," in a cheerful, gentle, and kindly way [1]. We soon discovered that friendship in the Arab world also meant extreme and unconditional loyalty. That loyalty even went so far as never refusing a request, no matter what the request. It is not uncommon for Arab students to copy the work of a "friend" or to help a "friend" by supplying examination answers. The Western idea of cheating was new to our students, and led to many discussions about how best to "help" their "friends" discover their own solutions to problems. Engineering ethics is explored in STEPS II, and the students are given case studies to evaluate. Respect and loyalty are identified by the students as valuable to a successful team. A 1997 study by Karen Tonso [2] at the Colorado School of Mines identifies "Three Principles of Ethical Teamwork" as "Respect one's teammates," "Do sound engineering," and "Communicate the real work done." Our students would add "Be loyal to your friends."

This fierce loyalty led to positive results as well. After a semester of tardiness and spotty attendance on the part of some of the students, the mentors developed an attendance policy that penalized not only the perpetrator of the attendance offense, but the perpetrator's teammates. Threatened with the prospect of lowering their "friends" grades, attendance and promptness rose to near perfection!

Eberhardt [3] has identified two sets of functions that are necessary to operate successfully as a team. Task functions, critical to product quality, focus on implementing tasks aimed at the overall team goal. Team functions, critical to team satisfaction, help teams to operate efficiently and effectively. The synthesis of these functions leads to successful problem solving, organizing and marketing. Team functions critical to team satisfaction help teams to operate effectively and as a team. Task functions included Initiating, Information Seeking, Information Giving, Clarifying, and Summarizing. Team functions are Harmonizing, Gate Keeping, Encouraging, Compromising, and Standard Setting. In this context, our Arab students' team functions were stronger than their task functions. This can be attributed to cultural tribal dynamics that encourage harmony, avoidance of conflict, and the fierce loyalty previously mentioned. According to Beamer [4], "the underlying power structure is the extended family or clan." These "families" of students encouraged efficient and communicative teamwork. Task functions improved over the course of the semester as delivery deadlines approached and information was identified as essential to production.

Tuckman identified four stages of team development: Forming, Storming, Norming, and Performing. While this model is consistent with Western team process, our Arab student teams refrain from conflict, and never "storm" [5]. This behavior is proscribed by the Quran, which requires mutual cooperation, sincerity, and humility among "brothers" [1].

\footnotetext{
"Proceedings of the 2005 American Society for Engineering education Annual Conference \& Exposition Copyright $\mathrm{C} 2005$, American Society for Engineering Education"
} 


\section{TeAm GoAls AND ContraCts: MeASURING EXPECTATIONS AND RECORDING SATISFACTION}

Our Arab teams were required to write out goals for their teams and to supply a team "contract" outlining expectations for all members. These were not largely different from Western models. The students wanted to learn, to have fun, and receive good grades. They expected their teammates to attend meetings, listen to one another, and respect one another. The students' satisfaction with their teammates and with the design experience was measured at the end of each semester with peer and course evaluations. A 1998 study at the Colorado School of Mines by Knecht [6] measured students' perceptions of their team experiences at the beginning and end of the semester. Like their CSM counterparts, the Arab students' satisfaction with their peers and the course as a whole was directly related to successful team interactions during the design process resulting in a high quality product. Stewart, Manz, and Sims [7] agree that such a teamwork model that measures input and output conditions can be useful for addressing issues related to teamwork. Student comments about the course were very positive. They gave high marks to mentoring, hands-on projects, and the practical value of the program to their future careers.

\section{TEAMBUILDING EXERCISES}

Arab students love to play teambuilding games. Teambuilding exercises in STEPS I and II are designed to introduce the students to working together in teams to solve open-ended problems. Some of the games are design-and-build: paper towers, paper bridges, or paper airplanes, while others involve data analysis. In one game called "Lost in the Amazon Jungle" students must decide on what 5 survival tools (out of a list of 25) will best help them be rescued. The Arab students use colorful personal negotiation to convince their teammates to choose one tool over another. A game brought over from Dr. Robert Knecht's EPICS files is "Nuclear Popcorn." Students must work as a team to lift buckets of popcorn (nuclear popcorn) without spilling the deadly kernels. Another game involves providing the students with multiple objects for the intent of making a "gizmo." A soup can, string, paper, rubber bands, and other miscellaneous objects are provided, and the students are instructed to create and name their invention.

\section{Bringing InTERCULTURAL AWARENESS to OUR ARAB STUDENTS}

Since many of our Arab students have never traveled out of the United Arab Emirates, the notion of some day working with international teams of engineers in foreign lands is both intriguing and a source of anxiety. The Arab culture, like most, owns its religion, customs and language with pride, and is perplexed by the strange manners and notions of the rest of the world. Their lives deeply and daily influenced by Islamic religion and law (no separation of church and state), and with extended families as their primary subculture, the students' lives were thus far highly provincial. In the new STEPS II program, the students are introduced to the whys and hows of getting along with people unlike themselves in their future careers.

Arab students' ideas about the rest of the world are largely formed by watching movies and television, so they have variously distorted and unrealistic expectations about the behavior of people in foreign lands. For many, the Petroleum Institute is the students' first opportunity to interact directly with real people (as opposed to movie icons)- their instructors -- from various parts of the

\footnotetext{
"Proceedings of the 2005 American Society for Engineering education Annual Conference \& Exposition Copyright $\mathrm{C} 2005$, American Society for Engineering Education"
} 
globe. Imagine learning English from several different instructors with various accents and inflections, not to mention the shock of their first female instructor ever (the author!).

I think that my colleagues would agree that the students have been warm and welcoming, receptive, polite, and attentive. They are hospitable to strangers, and we were inducted very quickly into the society of "neighbors" in Arab culture. Being a good neighbor is very important to Muslims, and there is a proscribed etiquette for neighborly behavior. Honoring one's neighbors includes greeting them with smiles, helping them when they need help, and other acts of kindness. You don't have to be a Muslim to be a Muslim's "neighbor" [1].

This "neighborliness" helped the STEPS team introduce the role of the mentor. Despite the fact that they initially resist the idea of mentors (as opposed to the familiar lecturer) they appreciate and laud this new type of guidance. As Beamer and Varner [4] point out, "Arabs have a hard time dealing with people when there is no clear indication of who the leaders are." Once the students got used to the idea of the mentor as an authority figure, they enjoyed the more relaxed guidance.

STEPS II aims to broaden the students' perspectives by introducing them to the idea of ethnocentrism, along with exposure to cultural differences such as language, religion, customs, laws, ideas about time and space, and manners. While some of the students regard these discussions with grave reservation, others are curious about what time restaurants open in the US, what constitutes table manners in Turkey, the custom of gift-giving in Spain, or how not to impress your boss in Italy.

Over the course of the semester, the students come to appreciate how team diversity leads to team success. This concept translates well when talking about the potential for success on international teams.

\section{ENGINEERING DESIGN:}

\section{Trying Not to DisRupt Traditional Values While Learning Something NeW!}

Like their Western counterparts, Arab students resist the idea that there is more than one right answer to a problem. They are also highly competitive and territorial about their project designs. Although STEPS provides the students with a workshop and places to store their prototypes at the PI, the Arab students did not want to risk their ideas being pilfered by other teams before the competition at the end of the semester. Thus, models were produced at the final hour. Part of this was also due to procrastination and poor time management. An introduction to project planning and project management helped the students realize the value of time management, but they nevertheless continued to leave things to the last minute. However, they came through in the end, proud of their accomplishments, and with a desire to win the competition.

We discovered early on with the miniature solar race car project that the Arab students had very little experience working with their hands and working with tools. Many of them were also wealthy enough and wily enough to taunt the mentors about hiring out their project. The quality of the final products would indicate that the students did their own work, and learned something new about their own ingenuity.

\footnotetext{
"Proceedings of the 2005 American Society for Engineering education Annual Conference \& Exposition Copyright $\mathrm{C} 2005$, American Society for Engineering Education”
} 


\section{Communication in an Oral CUlture}

\section{Oral Presentation Skills}

Arab students are terrific conversationalists. They are intensely personal, and love to talk about themselves, their families, and their world. "It isn't surprising that self-congratulation and selfpraise are part of the exaggeration of Arabic speakers. Describing one's own accomplishments, the high status of one's friends, or the superiority of one's abilities in exaggerated terms is usual [5]." It is an oral culture, developed over centuries, during which story telling took the place of written literature. This attribute carries over extremely well in oral presentations that the students give on their projects. These presentations include project plans, progress reports, subsystems reports (redline sessions), and final reports on their project. Most Arab students are quite comfortable in front of an audience, and public speaking does not hold the fear that it does for Westerners. The conventional garb, the dishdash, hides a good deal of body language, so that the Arab students appear poised and confident. The STEPS program teaches the students to use technology to support their presentations. We caution them to use PowerPoint and overheads judiciously, in lieu of showing off their excellent speaking skills.

The students let this author know that, because of tribal beliefs, some of them would not be able to shake my hand at the beginning or end of a presentation. We worked this out by adding a "nod" as a greeting. Arabs' use of body space is more intimate than Westerners. Conversations are closer; touching (including hand-holding) between males is common.

\section{WRITING SKILLS}

One of the functions of the PI's Foundation Program is to convince our students of the importance of writing well in their careers. You can be the best engineer in the world, but without the ability to communicate your design, you cannot sell it. Thus, English language skills, both oral and written, are at the heart of all PI instruction. Writing in English is challenging for our Arab students. Although a student may appear very eloquent and articulate with the spoken word, translating onto paper is quite another test. According to Beamer and Varner [5], this is because Arabic language structure consists of a combination of ideas - like English phrases - and is difficult to encode into English. By the time the students reach the STEPS program, they have a wide range of competency levels. Since project work is performed by teams, the students generally pick the best writer on the team to produce the reports.

\section{GRAPHICS}

STEPS I and II introduce the students to SolidWorks as a tool for illustrating their designs. While this aspect of the program plays a large role in the EPICS program at CSM, our Arab students have some trouble with visualization [largely because of a lack of exposure to drawing in their earlier education]. Half of the semester is thus used up with remediation in visualization, with SolidWorks coming in later. The students generally enjoy this tool, but the designs are more rudimentary than their Western counterparts. Poster sessions at the end of the semester showcase the students' designs and are highlighted with both their free-hand sketching and their computer drawings.

\footnotetext{
"Proceedings of the 2005 American Society for Engineering education Annual Conference \& Exposition Copyright $\mathrm{C} 2005$, American Society for Engineering Education"
} 


\section{Pride, Praise, AND SPORTSManship}

Our Arab students love praise, and are hurt more by criticism than Westerners. They want to be liked, and they love to be admired. Grades are taken very personally, and it is not uncommon for students to persist in the attempt to have their grades raised. Nevertheless, at the final competition for the balsa wood bridges, the Arab students showed their good natures when defeated, their sense of humor when embarrassed, and their humility when in the winner's circle.

\section{SUMMARY}

The STEPS program at the Petroleum Institute in Abu Dhabi has thus far proven to be a fascinating experience in intercultural adaptation of a Western engineering design philosophy to a Middle Eastern academic setting. As expected, many of the paradigms that worked with the EPICS program at the Colorado School of Mines simply did not translate directly to the STEPS program at the Petroleum Institute. For instance, teamwork was enhanced by the etiquette of Arab friendship, while graphics were weakened by the lack of prior exposure to drawing. Oral presentations were superior as the result of an oral cultural orientation, while writing skills were naturally impeded by English as a second language. The design-and-build nature of the projects was hindered by a lack of familiarity with tools and construction techniques. Project management tools were easily assimilated. This author and her colleagues at the Petroleum Institute are constantly adapting and modifying the course content and delivery methodologies in order to provide appropriate learning outcomes for our students. Based on the experiences from the last academic year and our expectations for the coming years, we believe that the STEPS Program will provide students at the Petroleum Institute with a solid grounding in the theory and practice of design, and will also give our students the tools required to successfully tackle an open-ended engineering design problem and to effectively communicate their results. 


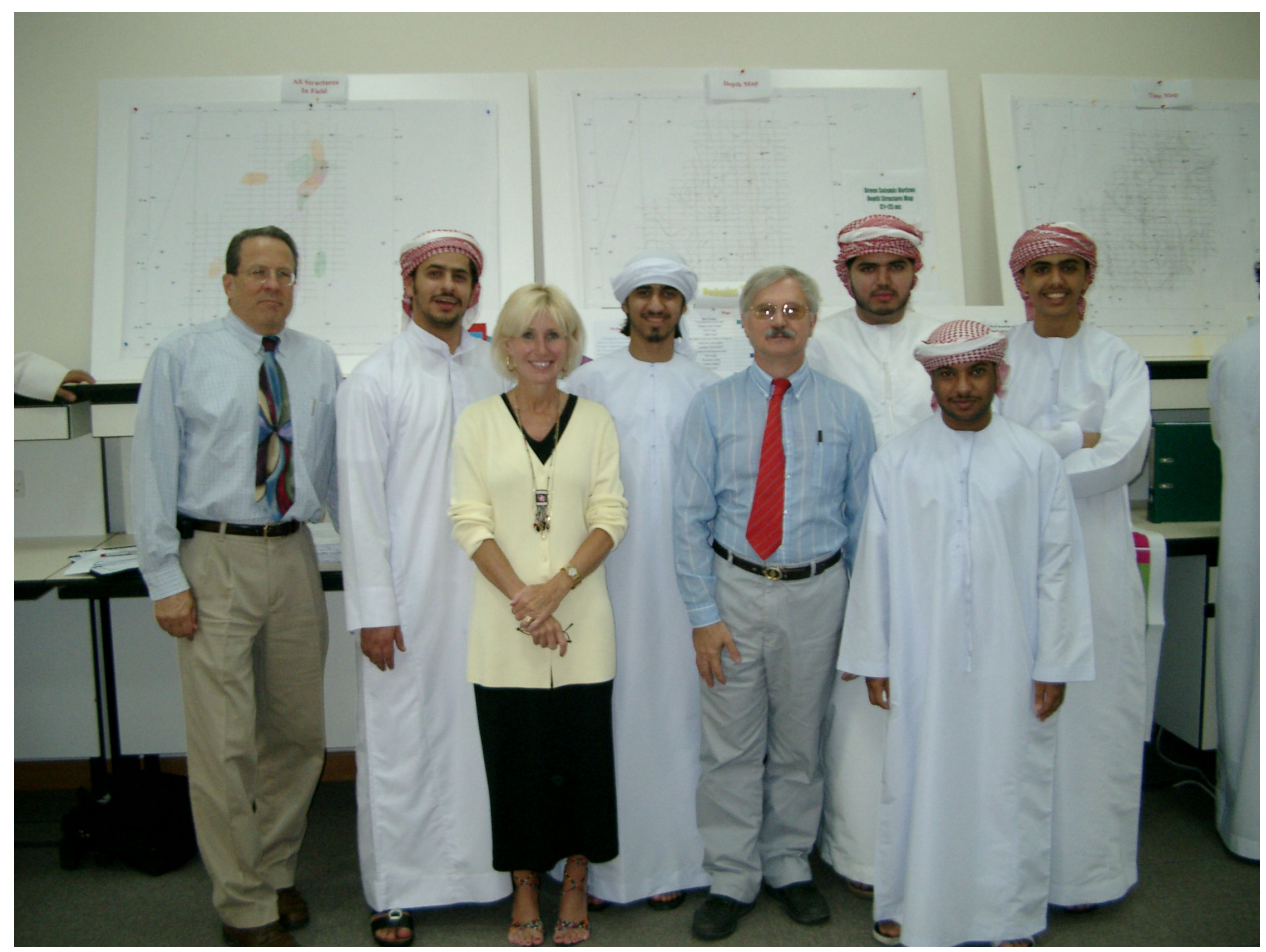

\section{FIGURE 2}

\section{STEPS II STUDENTS AND MENTORS ON PRESENTATION DAY}

\section{ACKNOWLEDGEMENTS}

Development of the STEPS Program at The Petroleum Institute was a collaboration between the Institute and The Colorado School of Mines. Special thanks to Dr. Robert M. Baldwin, Colorado School of Mines/Petroleum Institute Coordinator, and Dr. Robert D. Knecht, Director, EPICS Program, Colorado School of Mines.

\section{REFERENCES CITED}

1. Ash-Shulhoob, F., The Book of Manners, Darrussalm, Riyadh, 2003

2. Tonso, K.L., Constructing Engineers through Practice: Gendered Features of Learning and Identity Development, Doctoral Dissertation, University of Colorado-Boulder, Dissertation Abstracts International, 9800565, 1997

3. E berhardt, L.Y., (1987), Working with Women's Groups, Vol. 1, Whole Person Association Inc, Duluth, Minnesota.

4. Beamer, L and Varner, I., Intercultural Communication in the Global Workplace, McGrawHill, 1995

5. Tuckman, Bruce, "Developmental Sequence in Small Groups," Psychological Bulletin, 63 
6. Knecht, R., An Engineering Approach to the Assessment of the First-Year Design

Sequence at the Colorado School of Mines, ASEE Conference, Seattle, Washington,1998.

7. Stewart, G.L., Manz, C.C., and Sims, H.P., (1999), Team Work and Group

Dynamics, John Wiley and Sons, Inc., New York, New York

\section{REFERENCE CONSULTED}

Lewis, R.D., When Cultures Collide, Nicholas Brealy Publishing, London, 1999

\section{BIOGRAPHY}

Suzanne Scott received her B.A. in English and Education from Drury College, her M.A. in English from Washington University, and Ph.D. in English from the University of Denver. She is a former Coordinator of the EPICS (Engineering Practices Introductory Course Sequence) Program at the Colorado School of Mines under the Directorship of Dr. Robert Knecht. In an effort to establish an engineering design program in higher academia in the Middle East, she was enlisted by CSM to help develop the STEPS (Strategies for Team-based Engineering Problem Solving)

Program at The Petroleum Institute in Abu Dhabi, United Arab Emirates. She currently resides in Abu Dhabi and can be reached at The Petroleum Institute, PO Box 2533,Abu Dhabi, United Arab Emirates, and at sscott@pi.ac.ae.

\section{ACKNOWLEDGEMENTS}

Development of the STEPS Program at The Petroleum Institute was a collaboration between the Institute and The Colorado School of Mines. Special thanks to Dr. Robert M. Baldwin, Colorado School of Mines/Petroleum Institute Coordinator, and Dr. Robert D. Knecht, Director, EPICS Program, Colorado School of Mines. 